\title{
Days Needed to Characterize the Healthfulness of a Typical Dinner Meal in Direct Observational Research: Mixed Methods Study
}

\author{
Allan Tate ${ }^{1}$, PhD; Amanda Trofholz ${ }^{2}$, MPH; Michael Miner ${ }^{2}$, PhD; Jerica Berge ${ }^{2}$, CFLE, MPH, LMFT, PhD \\ ${ }^{1}$ Department of Epidemiology and Biostatistics, College of Public Health, University of Georgia, Athens, GA, United States \\ ${ }^{2}$ Department of Family Medicine and Community Health, University of Minnesota Medical School, University of Minnesota, Minneapolis, MN, United \\ States
}

\section{Corresponding Author:}

Allan Tate, $\mathrm{PhD}$

Department of Epidemiology and Biostatistics

College of Public Health

University of Georgia

202 BS Miller Hall

101 Buck Rd, Health Sciences Campus

Athens, GA, 30602

United States

Phone: 17065426317

Email: allan.tate@uga.edu

\section{Abstract}

Background: Prior research around the home meal environment has demonstrated that family meals are associated with positive health outcomes for children and adolescents. Researchers have begun using direct observational methods to understand key aspects of family meals such as meal healthfulness and family meal frequency to explain the protective nature of family meals. Direct observational research, however, can be resource intensive and also burdensome for participants. Information about the number of days needed to sufficiently characterize typical meal healthfulness using direct observational research methods is needed.

Objective: The current study aimed to produce guidance about the number of meals necessary to approximate typical meal healthfulness at the family dinner meal occasion in a direct observational, mixed methods study of the home food environment.

Methods: Families were recruited between 2012-2013 from primary care clinics in the Minneapolis-St Paul metropolitan area $(\mathrm{N}=120)$. A total of 800 meals were collected as part of the Family Meals LIVE! mixed methods study. The Healthfulness of Meal Index was used to evaluate meal dietary healthfulness of foods served at 8 family meal occasions. Participating families were provided an iPad (Apple Inc) and asked to video-record 8 consecutive days of family dinner meals with a minimum of two weekend meals. After the meal, families completed a meal screener, which is a self-reported, open-ended measure of the foods served at the meal.

Results: Weekend and weekday meals differed in their measurement of meal healthfulness, indicating that at least one weekday and one weekend day are necessary to approximate meal healthfulness. Single-day measurement mischaracterized the strength of the relationship between the quality of what was served and intake by almost $50 \%$, and 3 to 4 observation days were sufficient to characterize typical weekly meal healthfulness $(r=0.94 ; P<.001)$.

Conclusions: Relatively few direct observational days of family meals data appear to be needed to approximate the healthfulness of meals across 1 week. Specifically, 1 weekday and 1 weekend observation are needed, including a total of 3 to 4 days of direct observational meal data. These findings may inform future direct observational study designs to reduce both research costs and participant burden in assessing features of the meal environment.

(JMIR Pediatr Parent 2021;4(1):e22541) doi: 10.2196/22541

\section{KEYWORDS}

meal healthfulness; direct observation; family meals; well-being; diet; food 


\section{Introduction}

Having frequent family dinner meals has consistently been associated with a number of beneficial health outcomes for children, including reduced risk of being overweight [1-3] and healthy diet quality [4-10]. Additionally, quality of the emotional atmosphere [11,12] during family meals and quality of the food served during these meals [13] have been previously characterized as pathways that affect child weight and health outcomes. Direct observational research methods (ie, video recording) are becoming more common in family meals research because they overcome the reporting bias found in commonly used survey-based measures, allowing for a more in-depth and robust picture of the characteristics (eg, interpersonal interactions, meal healthfulness) of family meals that may contribute to child and adolescent health $[11,14]$. However, the impact of both the timing of the direct observational measurement and duration of the observational measurement period on estimates of meal healthfulness have not been examined.

In the current methodological study, the Healthfulness of Meal Index (HOM), implemented in the Family Meals LIVE! direct observational study [15], was used to answer the research question: how many days of direct observation of the foods served at family dinner meals are needed to characterize "typical" healthfulness of the meal to preserve resources and reduce participant burden? Family dinner meals were defined as an evening meal eaten in the home environment with the majority of family members present. The study further examined if weekends and weekdays influence meal healthfulness and at what number of days the addition of an observation day becomes unnecessary to characterize relationships with child dietary intake. We hypothesized that weekday and weekend day meal healthfulness estimates would differ due to changes in the home meal environment when children are not at school or when parents are not generally at work. We also hypothesized that estimates incorporating fewer days of observations would be weakly correlated with estimates derived from a full week of dinner meals. Results of the current study address a salient public health nutrition research need of providing pragmatic design guidance that could result in improved measurement.

\section{Methods}

\section{Sample Population}

Data collected from Family Meals LIVE! [15], a direct observational, mixed methods study, were used to measure the healthfulness of foods served at 8 meal occasions. The University of Minnesota's Institutional Review Board Human Subjects Committee approved the study protocol. Families ( $N=120)$ were recruited between 2012 and 2013 from 4 primary care clinics in the Minneapolis-St Paul metropolitan area that serve a racially/ethnically diverse, urban population of primarily low-income families. Participating families were provided an iPad (Apple Inc) and asked to video-record 8 consecutive days of family dinner meals with a minimum of two weekend meals. Only dinner meals in the home were recorded because of privacy issues. At the start of each meal, families spoke into the camera to indicate what foods were being served. After the meal, families completed a meal screener, which is a self-reported, open-ended measure of the foods served at the meal. Comprehensive study procedures have been described elsewhere $[11,13]$.

In total, 800 meals were available for analysis [13]. Families were asked to record meal occasions over consecutive days, and recordings were taken every 1.8 days on average (SD 0.89), indicating good participant compliance with data collection procedures and minimal lack of family meals or meals outside of the home. A 1-day washout period was employed to allow families to acclimate to the study procedures and recording equipment.

\section{Direct Observational Research}

Previous studies have shown that direct observational research conducted in the home using unstructured observations (eg, play, routines) has more predictive validity and reliability compared to laboratory settings using structured observations (eg, tasks given to participants) and allows participants to acclimate and exhibit less reactivity [16-18]. The lengthened, 8-day observation window has been shown to offer advantages over cross-sectional designs, which include the measurement of weekday and weekend meals, the capture of variability in the healthfulness of weekly meals, and more reliable and objective measurement of family meal occasions [16-18].

\section{Healthfulness of Meal Index}

The HOM, created for the Family Meals Live! study and adapted from the Healthy Eating Index 2010 [19], was used to assess family meal healthfulness $[13,15,20]$. The HOM assesses 7 categories of foods served at meals: fruit, vegetables, dark green vegetables, dairy, protein, high sodium foods (reverse scored), and added sugars (reverse scored). A present-or-absent format is used to score the HOM, the components are summed, and a total of 9 points are available (the fruit and vegetable categories can each receive a total of 2 points). A higher total score is reflective of a more healthful family meal with regards to foods served. To calculate the HOM score, 3 research members (including 2 registered dietitians) watched each video-recorded meal to code the foods present [13]. The self-report meal screener was also used to corroborate the foods seen in the videos. Because the HOM evaluates meal dietary healthfulness, all foods present were coded even if they were not consumed by all family members.

\section{Meal Healthfulness Permutation Measures}

Permutations were constructed to evaluate study conditions (timing of measurement and duration of measurement period) that researchers implemented at the design stage of direct observational studies. First, a permutation was calculated to examine how adding observation days affects the HOM relative to a measure that incorporates all observation days. In all, 13 HOM permutations were calculated: a full-week index of average meal healthfulness (this was the primary reference permutation), 6 indices adding 1 additional day on the front end of the observation window (permutation 1: day 1 only; permutation 2: average of days 1 and 2; permutation 3: average of days 1 through 3 ; etc.), and 6 permutations adding 1 
additional day beginning with the last observation day (measure 1: day 7 only; measure 2: average of days 7 and 6; measure 3: average of days 7,6 , and 5 etc). The primary reference permutation was computed assuming that capturing more dinner meals would reduce the random variation in the composition of foods that are served across days to obtain a measure of typical meal healthfulness. Relative to this comprehensive direct assessment of meal healthfulness, a measure containing fewer observation days that is highly correlated with the full measure may sufficiently characterize typical family meal healthfulness without excess resource investment.

\section{Statistical Analysis}

Survey estimation procedures were performed for each permutation of the HOM to determine whether the means differed by day of week, with sampling weights being applied to obtain population average meal healthfulness measures generalizable to the 4 clinics from which families were recruited. Effect consistency in the relationship between the HOM and dietary intake and family meal frequency were examined in sensitivity analyses to evaluate the presence of measurement error in permuted variables with a fewer number of observation days. A third correlational analysis was performed to evaluate the strength of the linear relationship between each HOM permutation. Comparisons between each reduced measure and the full reference measure were examined to determine how many days of additional meal recordings were needed to approximate the full reference measure. The intraclass correlation coefficient (ICC; 0.663 ) was calculated to evaluate consistency across the permutations within families. Pearson correlation coefficients above the ICC were used to visually evaluate at what points the permutations with fewer measurement days approximated the measure incorporating all days. All analysis and data management were performed in Stata 13.1 SE (StataCorp).

\section{Results}

The coefficient of variation for the single-day estimate of meal healthfulness was $39.3 \%$ (mean 3.3, SD 1.3) and declined to $27.2 \%$ as days were added to compute the full reference measure containing all observation days (mean 3.2, SD 0.9). Adding observation days increased the precision of the sample measure, and dispersion around the mean stabilized when 3 observation days were included. The full permutation was overall similar for weekend days (mean 3.1, SD1.4) compared with only weekday observations (mean 3.2, SD 0.9). The permutation variables (day 1 and day 7) which corresponded to measures that would be derived from a 1-day, cross-sectional study design indicated that weekend meal healthfulness was higher in one weekday contrast and less healthy in the other weekday contrast. An evaluation of the noncompliance pattern indicated that meal healthfulness became increasingly difficult to ascertain for more than five meals for the total sample. Specifically, $96.7 \%$ of the sample (116/120) provided enough meal recordings to calculate the 5-7-day meal healthfulness permutation, and $78.3 \%$ of the sample (94/120) provided a final meal (seventh meal) recording needed to calculate the final meal healthfulness permutation.

The relationships between quality of foods served, dietary intake, and frequency of family meals were examined. The dietary intake association was strongly attenuated when fewer observation days were used to estimate meal healthfulness (Table 1). Compared to the association observed when 4 days were used to compute meal healthfulness, the single-day measure of association was $-48 \%$ weaker. By 4 days, the observed relationship between meal healthfulness and dietary intake was consistent with associations that included additional observation days. There was no evidence that the association between meal healthfulness and family meal frequency was strengthened or weakened according to how many meal healthfulness observation days were used. There was some evidence that inference would differ when adding observation days (ie, the statistical significance was not met at a $P$ value of $<.05)$.

Permutations of HOM were calculated by averaging the HOM scores calculated using 1 to 7 direct observation days. The bivariate associations between each permuted score and the Healthy Eating Index 2010 were examined. Increasing the number of direct observation days used to characterize the healthfulness of foods served (HOM) was positively correlated with healthy dietary intake of the participant child for all permutations (7-day permutation $P=.001$; Table 1). The magnitude of the associations grew as more observation days were included, and they remained similar after 3 or 4 observation days were added, suggesting that about 4 observation days may be sufficient to characterize how the healthfulness of food served at meals is related to child dietary intake.

Effect sizes expressed as correlation coefficient $r$ were examined to evaluate the strength of the linear relationship between the permutations using fewer than 7 observation days and the permutation incorporating all observed meals over the observation period (Table 2). Results indicated that the linear relationship between measures (starting with a single day and adding additional days) grew stronger as more observation days were added. A second analysis (removing the first observation day until only the last observation day was used) indicated a consistent pattern. Meals occurring farther apart (ie, the day 1 permutation and the day 7 permutation, each of which use a single observation day), were weakly correlated $(r=0.36)$, indicating meal healthfulness may vary across time. Permutations calculated from days closer together were strongly related (day 1 permutation and the permutation including both day 1 and day 2: $r=0.80$; permutation including day 6 and 7 and the day 7 permutation: $r=0.82$ ). The within-family ICC of all 13 permutations was moderate to strong (ICC 0.663 ), indicating moderate variation in family meal healthfulness. Four observation days sufficiently characterized the typical weekly meal healthfulness observed in the full measure $(r=0.94)$. 
Table 1. Association between the number of direct observation days in the healthfulness of meal index permutation and the Healthy Eating Index 2010 and weekly family meal frequency: $(\mathrm{N}=120)$ households (caregivers and children) recruited from Minneapolis-St Paul primary care clinics between 2012 and 2013.

\begin{tabular}{|c|c|c|c|c|}
\hline \multirow{2}{*}{$\begin{array}{l}\text { Number of } \mathrm{HOM}^{\mathrm{a}} \text { permutation observation } \\
\text { days }\end{array}$} & \multicolumn{2}{|c|}{ Healthy Eating Index 2010} & \multicolumn{2}{|c|}{ Weekly family meal frequency } \\
\hline & $\begin{array}{l}\text { Mean response } \\
(95 \% \mathrm{CI})\end{array}$ & $P$ value & $\begin{array}{l}\text { Mean response } \\
(95 \% \mathrm{CI})\end{array}$ & $P$ value \\
\hline 1 day & $1.4(0.12$ to 2.61$)$ & $.03^{\mathrm{b}}$ & $0.3(0.03$ to 0.61$)$ & .03 \\
\hline 2 days & $1.9(0.39$ to 3.39$)$ & .01 & $0.4(0.07$ to 0.75$)$ & .02 \\
\hline 3 days & 2.3 (0.74 to 3.77$)$ & .004 & $0.3(-0.04$ to 0.66$)$ & .08 \\
\hline 4 days & $2.6(1.15$ to 4.13$)$ & .001 & $0.3(-0.06$ to 0.68$)$ & .10 \\
\hline 5 days & 2.4 (0.86 to 3.84$)$ & .002 & $0.2(-0.11$ to 0.58$)$ & .18 \\
\hline 6 days & 2.5 (0.97 to 4.01$)$ & .002 & $0.3(-0.09$ to 0.62$)$ & .14 \\
\hline 7 days & $2.6(1.05$ to 4.07$)$ & .001 & 0.3 (-0.04 to 0.68$)$ & .08 \\
\hline
\end{tabular}

${ }^{\mathrm{a}} \mathrm{HOM}$ : Healthfulness of Meal Index.

${ }^{\mathrm{b}}$ Numbers in italics indicate significance at a $P$ value $<.05$.

Table 2. Family meal healthfulness permutation measures with pairwise Pearson correlations. Correlation coefficients $r$ are all significant at $P<.001$.

\begin{tabular}{|c|c|c|c|c|c|c|c|c|c|c|c|c|c|}
\hline $\begin{array}{l}\text { Permutation } \\
\text { variable }\end{array}$ & Day $1, r$ & $\begin{array}{l}\text { Days 1- } \\
2, r\end{array}$ & $\begin{array}{l}\text { Days 1- } \\
3, r\end{array}$ & $\begin{array}{l}\text { Days 1- } \\
4, r\end{array}$ & $\begin{array}{l}\text { Days 1- } \\
5, r\end{array}$ & $\begin{array}{l}\text { Days 1- } \\
6, r\end{array}$ & $\begin{array}{l}\text { All } \\
\text { Days, } r\end{array}$ & $\begin{array}{l}\text { Days 2- } \\
7, r\end{array}$ & $\begin{array}{l}\text { Days 3- } \\
7, r\end{array}$ & $\begin{array}{l}\text { Days 4- } \\
7, r\end{array}$ & $\begin{array}{l}\text { Days } \\
5-7, r\end{array}$ & $\begin{array}{l}\text { Days } \\
6-7, r\end{array}$ & $\begin{array}{l}\text { Day 7, } \\
r\end{array}$ \\
\hline Day 1 & $-^{a}$ & & & & & & & & & & & & \\
\hline Days 1-2 & 0.80 & - & & & & & & & & & & & \\
\hline Days 1-3 & 0.70 & 0.90 & - & & & & & & & & & & \\
\hline Days 1-4 & 0.64 & 0.83 & 0.93 & - & & & & & & & & & \\
\hline Days 1-5 & 0.60 & 0.78 & 0.90 & 0.97 & - & & & & & & & & \\
\hline Days 1-6 & 0.57 & 0.76 & 0.89 & 0.95 & 0.98 & - & & & & & & & \\
\hline All days & 0.57 & 0.76 & 0.88 & 0.94 & 0.96 & 0.98 & - & & & & & & \\
\hline Days 2-7 & 0.37 & 0.63 & 0.80 & 0.88 & 0.92 & 0.95 & 0.97 & - & & & & & \\
\hline Days 3-7 & 0.34 & 0.48 & 0.70 & 0.81 & 0.87 & 0.90 & 0.93 & 0.96 & - & & & & \\
\hline Days 4-7 & 0.34 & 0.46 & 0.56 & 0.72 & 0.80 & 0.84 & 0.88 & 0.90 & 0.94 & - & & & \\
\hline Days 5-7 & 0.33 & 0.48 & 0.59 & 0.62 & 0.73 & 0.80 & 0.86 & 0.88 & 0.89 & 0.92 & - & & \\
\hline Days 6-7 & 0.31 & 0.46 & 0.52 & 0.52 & 0.52 & 0.65 & 0.73 & 0.74 & 0.74 & 0.76 & 0.86 & - & \\
\hline Day 7 & 0.36 & 0.43 & 0.43 & 0.44 & 0.45 & 0.45 & 0.61 & 0.61 & 0.61 & 0.67 & 0.72 & 0.82 & - \\
\hline
\end{tabular}

${ }^{\mathrm{a}}$ Not applicable.

\section{Discussion}

\section{Principal Findings}

Study results were consistent with our hypothesis that a fewer number of direct observation days would be sufficient to characterize typical weekly meal healthfulness. We also found evidence that including both weekday and weekend day family dinner meals differed in healthfulness across a week-long observation period. Single-day and 2-day observations of meal healthfulness may be inappropriate for generalizing about the healthfulness of foods served at dinner meal occasions over the course of a week. In addition, correlational analyses indicated that when using just 2 days of data, the fewer-day permutations were strongly correlated $(r>0.70)$ with the full 7-day measure. This is in part because meal healthfulness was moderately to highly correlated within the family. Thus, it is not surprising that adding a fourth, fifth, and sixth day of observational data provided little additional information about the healthfulness of foods served. Using 3- or 4-day observations of family meal healthfulness appeared to maximize measurement reliability and to minimize the cost of data collection and respondent burden.

\section{Study Limitations and Strengths}

The study had several strengths, including the use of direct observational methods, consecutive observation of family meals, and a substantial number of meals $(\mathrm{N}=800)$ observed. Practical 
advantages are also noted, such as assessing measurement variability, providing new information about how to allocate staff time, and minimizing respondent burden. Replication studies are needed to provide support for the finding that relatively few observation days (ie, 1 weekend day and 1 weekday) are required, with the ideal number of days possibly being as few as 4; to test findings in a population with heterogeneous characteristics; and to assess meal healthfulness in multiple ways to avoid social desirability bias, recall error, and participant reactivity.

\section{Conclusions}

Findings from the current study suggest that relatively few direct observational days of family meals data are needed to approximate the healthfulness of meals across 1 week. Specifically, 1 weekday and 1 weekend observation at a minimum, along with 3-4 days of direct observational data, are needed. Findings from the current study may inform future direct observational study designs to reduce both research costs and participant burden.

\section{Acknowledgments}

This study is supported by the National Institute of Child Health and Human Development (no. R03HD084897 to JB) and the National Institute of Diabetes, Digestive and Kidney Disease (no. R21DK091619 to JB). The content in this study is solely the responsibility of the authors and does not necessarily represent the official views of the National Institute of Child Health and Human Development; the National Institute of Diabetes, Digestive and Kidney Disease; or the National Institutes of Health.

\section{Conflicts of Interest}

None declared.

\section{References}

1. Fulkerson J, Neumark-Sztainer D, Hannan P, Story M. Family meal frequency and weight status among adolescents: cross-sectional and 5-year longitudinal associations. Obesity (Silver Spring) 2008 Nov;16(11):2529-2534 [FREE Full text] [doi: 10.1038/oby.2008.388] [Medline: 18719674]

2. Larson NI, Neumark-Sztainer D, Hannan PJ, Story M. Family meals during adolescence are associated with higher diet quality and healthful meal patterns during young adulthood. J Am Diet Assoc 2007 Sep;107(9):1502-1510. [doi: 10.1016/j.jada.2007.06.012] [Medline: 17761227]

3. Gable S, Chang Y, Krull JL. Television watching and frequency of family meals are predictive of overweight onset and persistence in a national sample of school-aged children. J Am Diet Assoc 2007 Jan;107(1):53-61. [doi: 10.1016/j.jada.2006.10.010] [Medline: 17197271]

4. Gillman M, Rifas-Shiman S, Frazier A, Rockett HR, Camargo CA, Field AE, et al. Family dinner and diet quality among older children and adolescents. Arch Fam Med 2000 Mar;9(3):235-240. [doi: 10.1001/archfami.9.3.235] [Medline: 10728109]

5. Gable S, Lutz S. Household, parent, and child contributions to childhood obesity. Family Relations 2000 Jul;49(3):293-300. [doi: $10.1111 /$ j.1741-3729.2000.00293.x]

6. Fulkerson JA, Larson N, Horning M, Neumark-Sztainer D. A review of associations between family or shared meal frequency and dietary and weight status outcomes across the lifespan. J Nutr Educ Behav 2014 Jan;46(1):2-19. [doi: 10.1016/j.jneb.2013.07.012] [Medline: 24054888]

7. Hammons AJ, Fiese BH. Is frequency of shared family meals related to the nutritional health of children and adolescents? Pediatrics 2011 Jun;127(6):e1565-e1574 [FREE Full text] [doi: 10.1542/peds.2010-1440] [Medline: 21536618]

8. Neumark-Sztainer D, Larson NI, Fulkerson JA, Eisenberg ME, Story M. Family meals and adolescents: what have we learned from Project EAT (Eating Among Teens)? Public Health Nutr 2010 Jul;13(7):1113-1121. [doi: 10.1017/S1368980010000169] [Medline: 20144257]

9. Koszewski W, Behrends D, Nichols M, Sehi N, Jones G. Patterns of family meals and food and nutrition intake in limited resource families. Family and Consumer Sciences Research Journal 2011;39(4):431-441. [doi:

10.1111/j.1552-3934.2011.02080.x]

10. Burgess-Champoux TL, Larson N, Neumark-Sztainer D, Hannan PJ, Story M. Are family meal patterns associated with overall diet quality during the transition from early to middle adolescence? J Nutr Educ Behav 2009;41(2):79-86. [doi: 10.1016/j.jneb.2008.03.113] [Medline: 19304252]

11. Berge JM, Rowley S, Trofholz A, Hanson C, Rueter M, MacLehose RF, et al. Childhood obesity and interpersonal dynamics during family meals. Pediatrics 2014 Nov;134(5):923-932 [FREE Full text] [doi: 10.1542/peds.2014-1936] [Medline: 25311603]

12. Berge JM, Wickel K, Doherty WJ. The individual and combined influence of the "quality" and "quantity" of family meals on adult body mass index. Fam Syst Health 2012 Dec;30(4):344-351 [FREE Full text] [doi: 10.1037/a0030660] [Medline: 23148980]

13. Trofholz AC, Tate AD, Draxten ML, Rowley SS, Schulte AK, Neumark-Sztainer D, et al. What's being served for dinner? An exploratory investigation of the associations between the healthfulness of family meals and child dietary intake. $\mathrm{J}$ Acad Nutr Diet 2017 Jan;117(1):102-109 [FREE Full text] [doi: 10.1016/j.jand.2016.08.006] [Medline: 27666378] 
14. Jacobs M, Fiese B. Family mealtime interactions and overweight children with asthma: potential for compounded risks? J Pediatr Psychol 2007;32(1):64-68 [FREE Full text] [doi: 10.1093/jpepsy/js1026] [Medline: 16951307]

15. Trofholz AC, Tate AD, Draxten ML, Neumark-Sztainer D, Berge JM. Home food environment factors associated with the presence of fruit and vegetables at dinner: A direct observational study. Appetite 2016 Jan 01;96:526-532 [FREE Full text] [doi: 10.1016/j.appet.2015.10.019] [Medline: 26527254]

16. Gardner F. Methodological issues in the direct observation of parent-child interaction: do observational findings reflect the natural behavior of participants? Clin Child Fam Psychol Rev 2000 Sep;3(3):185-198. [doi: 10.1023/a:1009503409699] [Medline: 11225753]

17. Haidet KK, Tate J, Divirgilio-Thomas D, Kolanowski A, Happ MB. Methods to improve reliability of video-recorded behavioral data. Res Nurs Health 2009 Aug;32(4):465-474 [FREE Full text] [doi: 10.1002/nur.20334] [Medline: 19434651]

18. Paterson BL, Bottorff JL, Hewat R. Blending observational methods: possibilities, strategies, and challenges. International Journal of Qualitative Methods 2016 Nov 30;2(1):29-38. [doi: 10.1177/160940690300200103]

19. Guenther P, Kirkpatrick S, Reedy J, Krebs-Smith SM, Buckman DW, Dodd KW, et al. The Healthy Eating Index-2010 is a valid and reliable measure of diet quality according to the 2010 Dietary Guidelines for Americans. J Nutr 2014 Mar;144(3):399-407 [FREE Full text] [doi: 10.3945/jn.113.183079] [Medline: 24453128]

20. Trofholz AC, Tate AD, Miner MH, Berge JM. Associations between TV viewing at family meals and the emotional atmosphere of the meal, meal healthfulness, child dietary intake, and child weight status. Appetite 2017 Jan 01;108:361-366 [FREE Full text] [doi: 10.1016/j.appet.2016.10.018] [Medline: 27756638]

\title{
Abbreviations \\ HOM: Healthfulness of Meal Index \\ ICC: intraclass correlation coefficient
}

\author{
Edited by S Badawy; submitted 15.07.20; peer-reviewed by C Matthys, NP Joshi, A Serlachius; comments to author 20.09.20; revised \\ version received 13.11.20; accepted 19.02.21; published 24.03.21 \\ Please cite as: \\ Tate A, Trofholz A, Miner M, Berge J \\ Days Needed to Characterize the Healthfulness of a Typical Dinner Meal in Direct Observational Research: Mixed Methods Study \\ JMIR Pediatr Parent 2021;4(1):e22541 \\ URL: https://pediatrics.jmir.org/2021/1/e22541 \\ doi: $10.2196 / 22541$ \\ PMID: 33759788
}

(C)Allan Tate, Amanda Trofholz, Michael Miner, Jerica Berge. Originally published in JMIR Pediatrics and Parenting (http://pediatrics.jmir.org), 24.03.2021. This is an open-access article distributed under the terms of the Creative Commons Attribution License (https://creativecommons.org/licenses/by/4.0/), which permits unrestricted use, distribution, and reproduction in any medium, provided the original work, first published in JMIR Pediatrics and Parenting, is properly cited. The complete bibliographic information, a link to the original publication on http://pediatrics.jmir.org, as well as this copyright and license information must be included. 